\title{
AS PRINCIPAIS CARACTERISTICAS DO CONTRATO DE SEGUROS PRIVADOS
}

Ana Valeska Souza Bittencourt Lussari, Renata Poloni Sanches

Universidade do Oeste Paulista - UNOESTE, Curso de Direito, Presidente Prudente, SP. E-mail: valeskalussari2011@gmail.com

\section{RESUMO}

Como o direito é uma ciência dinâmica e se altera de acordo com o comportamento da sociedade, muitas vezes alguns fatores de relevância fogem da análise mais aprofundada sobre o tema. Esta pesquisa destaca os quatro principais focos deste contrato a fim de esclarecer cada dia mais as dúvidas que com frequência surgem em torno deste objeto jurídico. Após realizar pesquisa bibliográfica fica constatado que há muito mais a se aprofundar no referido assunto e que realmente além das funções indenizatórias do seguro, existe também uma questão moral e social em torno deste contrato que devem ser amplamente estudadas e destacadas a sociedade.

Palavras-chave: Contrato de seguro, indenização, direitos e obrigações, Boa-fé.

\section{THE MAIN INSURANCE CONTRACT FEATURES PRIVATE}

\begin{abstract}
As the right is a dynamic science and changes according to the behavior of society, often some of the relevant factors are beyond the further analysis on the topic. This research highlights the four focuses of this agreement in order to clarify each day more questions that often arise around this legal object. After performing literature becomes clear that there is much more to deepen in that subject and really beyond indemnity insurance functions, there is also a moral and social issue surrounding this contract to be widely studied and highlighted society.
\end{abstract}

Keywords: Insurance, indemnity, rights and outies, good faith. 


\section{INTRODUÇÃO}

O contrato de seguro tem como características jurídicas a bilateralidade, por gerar obrigações para ambas as partes (segurado e segurador), normalmente quando fala-se em dever de indenizar se lembra dos direitos, mas o contrato de seguros contém outras obrigações. Conforme descrito entre os artigos 757 e 802 do código Civil/2002, se resgata várias obrigações e direitos para ambas as partes.

Citando apenas alguns dos principais direitos e obrigações do segurado destaca-se o dever de cumprir com sua contraprestação em dinheiro, para com o segurador, referente a riscos assumidos; pulverizar o risco (resseguro ou cosseguro), respeitando seus limites técnicos; cumprir com as obrigações de mora (CC art.772); tomar todas as providencias necessárias assim que tomar conhecimento de evento previsto em contrato.

São direitos do segurador receber o prêmio referente ao contrato; isentar-se do pagamento, se restar comprovado dolo do segurado no seguro de dano, se restar comprovadas declarações inexatas ou a má-fé (CC art. 766); bem como limitar a indenização aos valores contratados (CC art.778) ou repor o bem; cessa as responsabilidades do segurador se o segurado estiver em mora no pagamento do prêmio, nos termos do art. 763, do Código Civil.

Há de se destacar, ainda, os direitos e deveres do segurado, tais como receber a indenização e a reparação do dano, equivalente a tudo aquilo que esteja dentro do risco contratado; receber reembolso de despesas feitas no interesse da seguradora para diminuir os prejuízos; ser assistido pelo segurador em caso de responsabilidade civil, cuja recuperação esteja amparada pelo contrato. São obrigações do segurado, agir na mais ampla e irrestrita boa-fé quanto as informações prestadas, sendo leal, respondendo às perguntas de avaliação de risco com exatidão e quanto do sinistro(CC art. 765 e 766), sendo que este item deve ser analisado juntamente com artigo 422 do código civil; pagar o prêmio convencionado, independente de risco ocorrido (CC art. 757 e 764) e responder pelos juros moratórios (CC art. 763); renunciar a tudo que possa aumentar os riscos ou que for contrário aos termos estipulados (CC art.768); comunicar ao segurador todo incidente que possa agravar o risco (CC art. 769 e parágrafos); comunicar a ocorrência de sinistro assim que souber da sua existência ( CC art. 771).

O objetivo deste artigo é tornar cada vez mais transparente as dualidades que envolvem os contratos de seguros privados.

\section{METODOLOGIA}

A metodologia utilizada para a pesquisa foi bibliográfica e exploratória, portanto qualitativo-teórica, uma vez que o artigo foi desenvolvido com base em materiais já publicados e as legislações em vigor. Segundo Gil (2012) esta característica refere-se em seu aspecto técnico é bibliográfica, uma vez que a mesma é definida como sendo aquela que 'é desenvolvida com base em materiais já publicados. Engloba, leituras, analise, interpretações de livros, textos legais, documentos ou fotocópias, mapas, fotos e manuscritos. '

Quanto aos Objetivos, a pesquisa caracteriza-se como exploratória, uma vez que segundo Gil (2009), os objetivos de uma pesquisa podem caracterizar-se como Exploratória, quando traz como definição que a familiarização com um assunto pouco conhecido ou pouco explorado, para que no final da pesquisa possa se conhecer mais deste assunto, estando apto a formular hipóteses. Por ser um tipo de pesquisa muito específica.

\section{RESULTADOS}

Considerando o introito deste artigo, verificou-se que o contrato de seguro é oneroso uma vez que o segurado paga o valor do "prêmio" ao segurador, havendo dispêndio financeiro. Várias doutrinas afirmam categoricamente que o contrato de seguro é aleatório, sendo até exemplo 
clássico em algumas, porém com a alteração do Código Civil realizada em 2002, classifica-o também como comutativo.

Para melhor compreensão, algumas definições doutrinárias para contrato aleatório e contrato comutativo: contratos aleatórios são os contratos em que o montante da prestação de uma ou de ambas as partes não pode ser desde logo previsto, por depender de um risco futuro, capaz de provocar sua variação, ou mesmo deixar de existir em virtude de um acontecimento incerto e futuro. (Diniz, Maria Helena, 2002).

A principal característica do contrato aleatório, seria o evento incerto e previsto. O Código Civil descreve em seus artigos 458 ao 461 as situações consideradas como aleatórias.

Silvio Rodrigues, (2004, p.332), afirma que o contrato de seguro é aleatório "não só por haver equivalência entre as prestações, como por não poder o segurado antever, desde logo, aquilo que receberá em troca da prestação que oferece".

No mesmo sentido, Orlando Gomes (1978, p.495), "contrato de seguro é aleatória, pois a vantagem do segurador depende de não ocorrer o sinistro ou de não se verificar o evento, em certo prazo".

Maria Helena Diniz (2002, p 459-460) afirma que "o ganho ou perda dos contraentes dependerá de fatos futuros e incertos, previstos no contrato, que constituem o risco."

Por sua vez o contrato comutativo tem como característica principal as prestações certas, previstas. Para Carlos Roberto Gonçalves (2012, p.74), contrato comutativo é aquele em que "as partes podem antever as vantagens e sacrifícios, que geralmente se equivalem decorrentes de sua celebração, porque não envolvem nenhum risco".

Comutativo é, portanto, o contrato em que cada uma das partes, além de receber de outra prestação equivalente à sua, pode apreciar imediatamente essa equivalência.

A partir da entrada do Código Civil de 2002, com a modificação do texto referente a este tipo de contrato, há possibilidade de uma interpretação diferente do contrato de seguros que deixou de ser essencialmente aleatório e passou a ter características comutativas.

Comparando os Códigos Civis de 1916 e 2002, verificou-se um grande avanço neste sentido. O Código Civil de 1916, em seu artigo 1.432, considerava contrato de seguro aquele pelo qual uma das partes se obriga para com a outra, mediante a paga de um prêmio, a indeniza-lo do prejuízo resultante de riscos futuros, previstos no contrato, enquanto que o Código Civil de 2002, afirma, em seu artigo 757, que pelo contrato de seguro, o segurador se obriga, mediante o pagamento de prêmio, a garantir interesse legítimo do segurado, relativo a pessoa ou a coisa, contra riscos predeterminados. Ratificando que somente pode ser parte, no contrato de seguro, como segurador, entidade para tal fim legalmente autorizada.

Sendo assim, a partir desta modificação onde o texto é alterado para garantir o interesse legítimo do segurado, encontra-se também no contrato de seguro uma característica comutativa, na medida em que ao contratar um seguro o consumidor busca tranquilidade e segurança imediatamente após a assinatura do contrato.

Neste contexto o vínculo obrigacional entre as partes, segurado e segurador, não acontece somente em caso de ocorrência de algum evento, mas no momento em que há o consentimento entre as partes, gerando obrigações recíprocas.

O corretor de seguros Fecher (2016) publicou em seu texto: "a maior mentira que os segurados contam", defendendo essa característica de forma enfática e convincente. Aborda justamente esta característica comutativa do contrato de seguro, quando defende que a maior mentira que ouvimos vem da frase: 'pago seguro há muitos anos e nunca usei!" quando na realidade usa-se sim, todos os dias.

Nesta abordagem Fecher (2016), defende que usar o seguro não significa receber uma indenização, usar o seguro significa ter a garantia que sua estabilidade financeira está protegida. Usar o seguro é ter a tranquilidade de sair sem se preocupar se você tem ou não a capacidade de 
absorver os prejuízos materiais ou pessoais que de alguma forma possam advir. Neste raciocínio o contrato de seguro seria comutativo, uma vez que a prestação se iniciaria no exato momento da concretização do contrato, onde o segurado pagou o prêmio em troca da tranquilidade de ter garantia de reembolso ou pagamento referente as coberturas e clausulas estipuladas no mesmo.

Quanto à forma, o contrato de seguro é classificado geralmente como formal, por exigir a forma escrita para se tornar válido, ser de execução sucessiva, de adesão visto que as cláusulas contratuais e a aceitação são previamente redigidas e regulamentadas pela entidade fiscalizadora do mercado segurador (SUSEP- Superintendência de Seguros Privados), órgão do Ministério da Fazenda.

Embora todo este contexto deixe o contrato de seguro caracterizado como formal, ele nasce do consentimento e da vontade das partes, portanto, antes de ser formal ele nasceu de forma consensual, o que faz com que ocorra divergência na doutrina.

Para Silvio Rodrigues (2002 p.335), trata-se de um contrato formal, pois exige a exibição da apólice ou bilhete do seguro.

Tal assertiva é amparada no artigo 758 do Código Civil/2002 onde o contrato de seguro prova-se com a exibição da apólice ou do bilhete do seguro, e, na falta deles, por documento comprobatório do pagamento do respectivo prêmio.

Já para Nery Júnior e Nery (2006, p.554), com base no mesmo artigo o contrato seria consensual: "o contrato de seguro é consensual. Conforme se vê do CC 758. Isto significa afirmar que está concluído para produzir seus efeitos, tão logo as partes reciprocamente tenham manifestado seu consentimento."

Considerando estes fatos, pode-se concluir que o contrato de seguro pode ser aleatório e consensual.

Quanto a boa-fé, a importância fica bem caracterizada na redação dos artigos 765 e 766, ambos do Código Civil/2002:

Art. 765. O segurado e o segurador são obrigados a guardar na conclusão e na execução do contrato, a mais estrita boa-fé e veracidade, tanto a respeito do objeto como das circunstâncias e declarações a ele concernentes.

E ainda,

Art. 766. Se o segurado, por si ou por seu representante, fizer declarações inexatas ou omitir circunstâncias que possam influir na /aceitação da proposta ou na taxa do prêmio, perderá o direito à garantia, além de ficar obrigado ao prêmio vencido.

Parágrafo único. Se a inexatidão ou omissão nas declarações não resultar de má-fé do segurado, o segurador terá direito a resolver o contrato, ou a cobrar, mesmo após o sinistro, a diferença do prêmio.

Nestes artigos supra mencionados do Código Civil/2002 restou claro que segurado e segurador devem observar com retidão o princípio da boa-fé, que as informações devem ser verídicas, na formação, quanto na conclusão como na execução, sob pena perda de direitos.

O que fica omisso na discussão em relação a estes dois artigos está na primeira parte do artigo 766 do Código Civil, onde é incluída mais uma parte na relação, que seria o representante legal do segurado, denominado como corretor de seguros.

Cabe acrescentar que a comercialização de seguros privados, conforme determina o órgão regulador do mercado segurador SUSEP (Superintendência de Seguros Privados) no Decreto-Lei ${ }^{0}$ 60.459, Capitulo X, regularizando a formação, a função e a competência é do corretor de seguros

0 artigo 723 do Código Civil/2002 estabelece que o corretor de seguros é obrigado a exercer a mediação com diligência e prudência que o negócio requer, prestando ao cliente 
espontaneamente, todas as informações e os esclarecimentos necessários acerca do seguro contratado.

Há ainda estabelecido no artigo 126 do decreto Lei $n^{0} 73 / 1966$ (BRASIL, 1966) a responsabilidade civil do corretor de seguros por condutas culposas, por omissão, imperícia ou negligencia, com danos e prejuízos causados aos segurados e às seguradoras.

Atualmente as demandas envolvendo os corretores de seguros, são na maioria baseadas no Código de Defesa do Consumidor, que pelo $\S 3^{\circ}$ do artigo 14 , define que o prestador de serviço responde independentemente da existência de culpa, pela reparação dos danos causados por defeitos relativos à prestação dos serviços, bem como por informações insuficientes ou inadequadas sobre sua fruição e risco.

O corretor de seguros, como representante legal do segurado é de relevante importância nesta relação contratual, uma vez que recebeu formação profissional específica para esta matéria, cabe a ele orientar corretamente quanto ao para preenchimento de todos os dados constantes da proposta feita ao segurador, visto que é dela que se origina os direitos e obrigações das partes. Como a maioria dos contratos de seguros são de adesão, cabe a este profissional a orientação correta quanto a todas as cláusulas, direitos e obrigações das partes.

De acordo com dados da Superintendência de Seguros Privados (SUSEP), 96 mil corretores de seguros, atuam no País, aproximadamente 40\% (38.4mil) desse total no Estado de São Paulo.

\section{DISCUSSÃO}

Contrato de seguro, apesar de amplamente estudado e discutido, ainda tem vários aspectos relevantes que vem sendo modificados com o decorrer do tempo, até mesmo pela rapidez e acesso que a nova realidade da informação e transformação social trouxe para o contexto atual do seguro.

O Código Civil/2002 (BRASIL, 2002) trouxe alterações importantes em seu texto, regulamentando várias questões quanto a esta modalidade de contrato entre os artigos 757 a 802 .

Para entrar no aspecto específico da questão, a definição trazida por Diniz (2002) quanto ao contrato de seguro elucida que "(...) é aquele pelo qual uma das partes (segurador) se obriga para com a outra (segurado), mediante pagamento de prêmio, a garantir-lhe interesse legítimo relativo a pessoa ou a coisa e a indenizá-la de prejuízo decorrente de riscos futuros, previstos no contrato". (Diniz, Maria Helena, 2002 p.457)

O contrato de seguros tem por princípios norteadores, além das cláusulas legais, a sinceridade e a boa-fé do contratante, que está disposta na regra geral dos contratos, nos termos do art. 422 do Código Civil que afirma obrigar-se os contratantes a guardar, assim na conclusão do contrato, como em sua execução, os princípio de probidade e boa-fé.

Esclarecida a definição de contrato, pode ser observado, dentro da redação do referido artigo, a existência de quatro questões: o dever da cia. seguradora de indenizar e garantir o interesse legítimo do segurado; o risco deve ser previsto e possível; a formalidade exigida; e a boafé entre os contratantes.

\section{CONCLUSÃO}

Desta forma fica caraterizada a importância de um estudo mais aprofundado do contrato de seguros, pois ele envolve vários fatores além dos mencionados que têm influência direta no desenvolvimento e sustentabilidade da sociedade, tendo em vista que pode-se atribuir ao seguro privado, além de todas as desenvolvidas neste texto, uma função social, no sentido de viabilizar a preservação do patrimônio quando do seguro de danos, bem como de propiciar que a estrutura familiar continue sendo assistida mesmo na ausência do mantenedor através das modalidades de seguros de pessoas, de previdências privadas e demais ramos. 


\section{REFERÊNCIAS}

DINIZ, Maria Helena, Direito Civil Brasileiro; Teoria das obrigações contratuais e extracontratuais. 3.vol.17 ed.- São Paulo: Saraiva. 2002 p.457

DINIZ, Maria Helena, Direito Civil Brasileiro; Teoria das obrigações contratuais e extracontratuais. 3.vol.17 ed.- São Paulo: Saraiva. 2002- Quadro sinótico constante das páginas 483-487 da mencionada obra.

GIL. Antonio Carlos. Métodos e Técnicas de Pesquisa Social. 6a Ed. São Paulo. Atlas S.A. 2012 GONÇALVES, Carlos Roberto. Direito Civil Brasileiro: Contratos e atos unilaterais. Vol. $3,9^{\circ} \mathrm{ed}$. São Paulo: Saraiva 2012.

NERY JUNIOR, Nelson e NERY, Rosa Mari de Andrade. Código Civil Comentado, $4^{\circ}$ ed., São Paulo, 2006, p.406 e p.554

RODRIGUES, Silvio. Direito Civil: dos contratos e das declarações unilaterais da vontade. Vol. 3, $30^{\circ}$ ed.São Paulo: Saraiva 2004, p.332 e p.357.

NERY JUNIOR, Nelson e NERY, Rosa Mari de Andrade. Código Civil Comentado, $4^{\circ}$ ed., São Paulo, 2006, p.406 e p. 554.

http://www.ambito-juridico.com.br/site/?artigo id=10754\&n link=revista artigos leitura

https://blogdorochaseguros.wordpress.com/2016/07/06/corretor-de-seguros-vende-o-que-elenao-compra/ http://www.susep.gov.br/menu/informacoes-ao-mercado/corretores-de-seguros-

http://www.thiagofecher.com.br/2016/06/a-maior-mentira-que-os-segurados-contam.htmlhttp://www.thiagofecher.com.br/2016/06/lei-das-associacoes-de-seguro-avanca-na.html 